San Jose State University

SJSU ScholarWorks

Master's Theses

Master's Theses and Graduate Research

Summer 2012

\title{
An Exploratory Study on the Relationship between Creativity, Religion, and Religiosity
}

Kim-lien Thi Nguyen

San Jose State University

Follow this and additional works at: https://scholarworks.sjsu.edu/etd_theses

\section{Recommended Citation}

Nguyen, Kim-lien Thi, "An Exploratory Study on the Relationship between Creativity, Religion, and Religiosity" (2012). Master's Theses. 4204. DOI: https://doi.org/10.31979/etd.cqkf-82dn

https://scholarworks.sjsu.edu/etd_theses/4204

This Thesis is brought to you for free and open access by the Master's Theses and Graduate Research at SJSU ScholarWorks. It has been accepted for inclusion in Master's Theses by an authorized administrator of SJSU ScholarWorks. For more information, please contact scholarworks@sjsu.edu. 


\title{
AN EXPLORATORY STUDY ON THE RELATIONSHIP BETWEEN CREATIVITY, RELIGION, AND RELIGIOSITY
}

\author{
A Thesis \\ Presented to \\ The Faculty of the Department of Psychology \\ San José State University \\ In Partial Fulfillment \\ of the Requirements for the Degree \\ Master of Arts
}

by

Kim-lien T. Nguyen

August 2012 
(C) 2012

Kim-lien T. Nguyen

ALL RIGHTS RESERVED 
The Designated Thesis Committee Approves the Thesis Titled

AN EXPLORATORY STUDY ON THE RELATIONSHIP BETWEEN CREATIVITY, RELIGION, AND RELIGIOSITY

by

Kim-lien T. Nguyen

APPROVED FOR THE DEPARTMENT OF PSYCHOLOGY

SAN JOSÉ STATE UNIVERSITY

August 2012

Dr. Gregory Feist Department of Psychology

Howard Tokunaga Department of Psychology

Jeffrey Danese Department of Religious Studies and Psychology 


\title{
ABSTRACT \\ AN EXPLORATORY STUDY ON THE RELATIONSHIP BETWEEN CREATIVITY, RELIGION, AND RELIGIOSITY
}

\author{
by Kim-lien T. Nguyen
}

Religiosity and religion are often said to be negative influences on one's creativity level. Creativity and religiosity have been looked at as a single dimension, which is a simplistic view. The purpose of this study was to examine the relationship between creativity and religiosity using scales that measure each construct multidimensionally. Religiosity was measured by one's level of inclusion of transcendent reality and symbolic interpretation of religious content. Creativity was evaluated in terms of fluency, originality, elaboration, abstractness, and resistance to premature closure. It was predicted that participants who exhibit high inclusion of transcendence and literal interpretation of religious content would be correlated with lower creativity. Creativity levels of Buddhists and Christians were also compared. It was predicted that Buddhists would have higher creativity levels than Christians based on Buddhists teachings involving impermanence and mindfulness. Participants completed three drawing tasks and surveys pertaining to their personality. Christian participants completed an additional religiosity scale. The dimensions of religiosity were related to some of the different dimensions of creativity. However, no difference in creativity scores was found between Buddhists and Christians. The results indicated that the religion with which one identifies may not be as important as one's commitment to religion when creativity levels are examined. 


\section{ACKNOWLEDGEMENTS}

This thesis could not have been completed without the help, support, and encouragement from so many people. First, I would like extend my heartfelt gratitude to my thesis committee, Dr. Gregory Feist, Howard Tokunaga, and Jeffrey Danese. A special thank you to my advisor, Dr. Feist, for his commitment and belief in my success.

Thank you to my family and friends. Dad, Anh, Hung, and Vi, you have been my motivation to work hard and push through the difficulties the past 2 years. Thank you to my many aunts, uncles, and cousins (especially NTLTN, Julie, and Tuyen). Thank you to my temple family, Ky Vien. You guys always gave me encouraging words, hours of laughter, and pictures that would take more than a thousand words to describe. Chi Tho, David, Diana, Nancii, Son, Hien, and Huyen, you guys are my rock. A big thank you to all my friends for their support, especially Tran, Nom, Mia, Tiffany, Christine, and Ingrid, who have been so patient with me. A special thank you to my San José friends, Tarhata, Jennifer, Bethany, Crystine, and Trey, for making San José my second home. I would also like to acknowledge my El Camino Community College family. Dr. Richard Mascolo, Dr. Amy Himsel, Julio Farias, and Dr. Angela Simon, thank you for encouraging me to pursue my goals. You all have remained a constant source of support and there are no words to express my appreciation.

Finally, I would like to dedicate my thesis to my mom. She showed me that above and beyond the hardships of life, you can lead a beautiful and fulfilling life. Her memory will continue to inspire me to be the best person I can possibly be and to live life with compassion, laughter, and dignity. 


\section{TABLE OF CONTENTS}

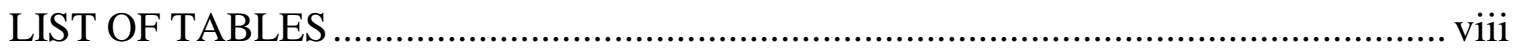

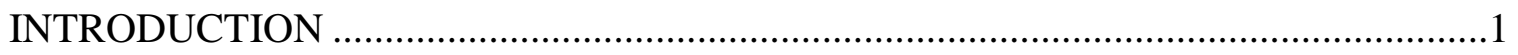

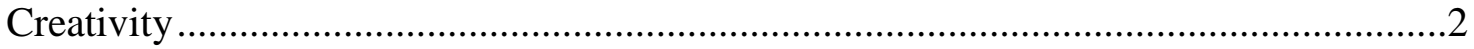

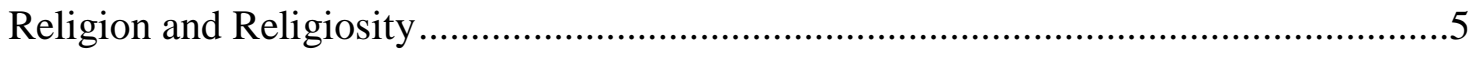

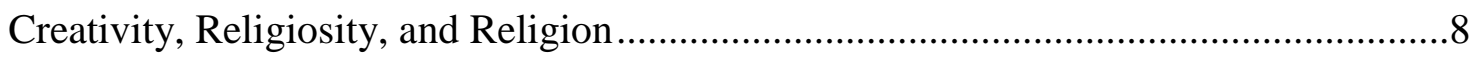

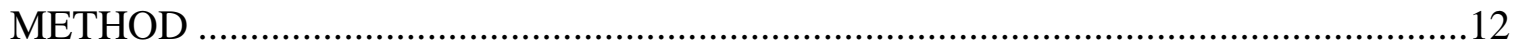

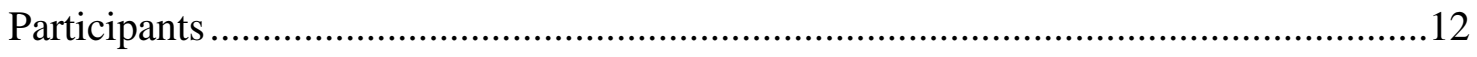

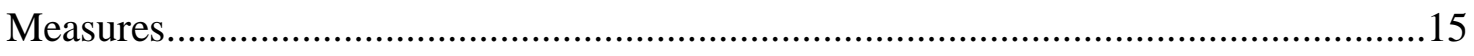

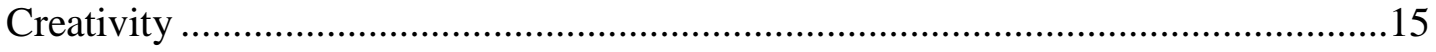

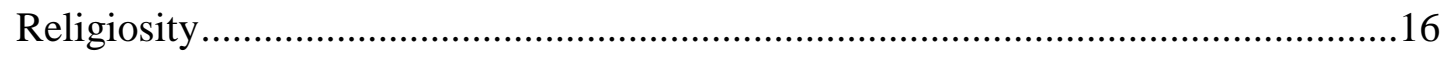

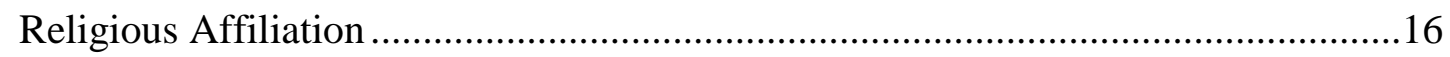

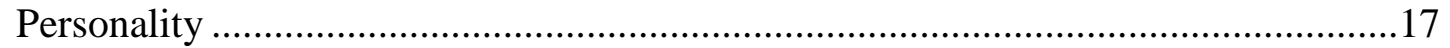

Procedure

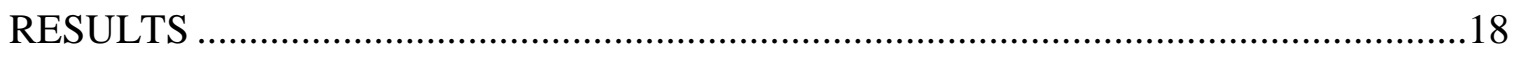

Hypothesis 1 ................................................................................................18

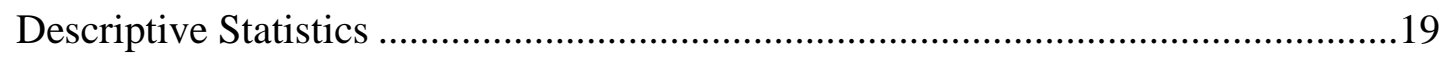

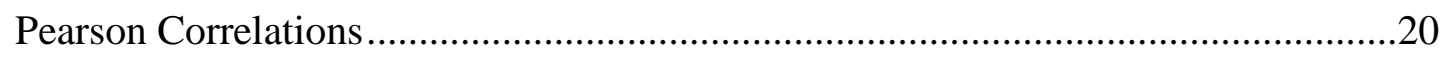

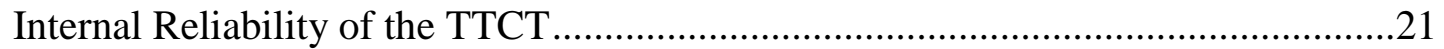

Regression Analyses .....................................................................................21

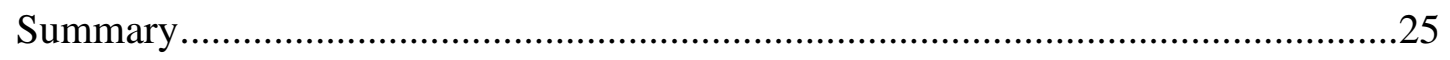

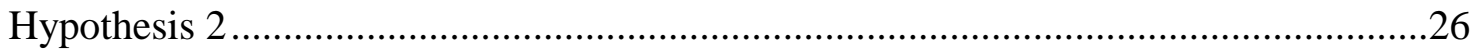

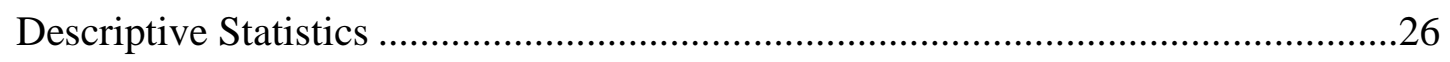

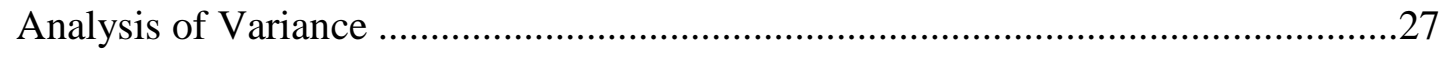

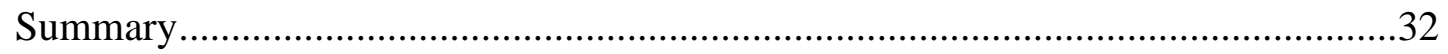

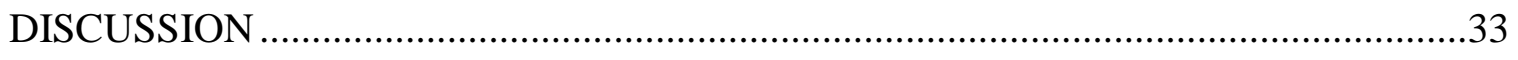

Implications of Findings.....................................................................................

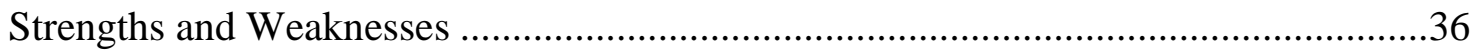




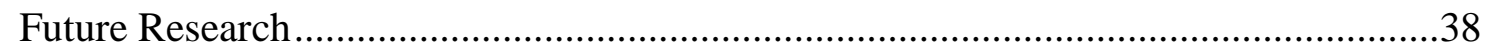

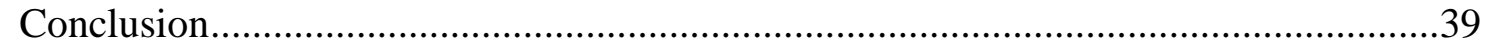

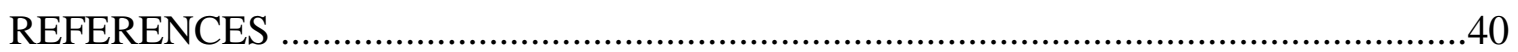

APPENDIX A: Demographic/Background Items .................................................45 


\section{LIST OF TABLES}

TABLE

PAGE

1. Descriptive Statistics for Demographic Variables for All Participants .14

2. Descriptive Statistics for Predictor and Criterion Variables for Christian Sample ......20

3. Intercorrelations between Predictor Variables for Christian Sample .........................21

4. Regression Analyses Summary Predicting Dimensions of Creativity ........................23

5. Descriptive Statistics for Variables in Buddhist and Christian Sample......................27

6. Analyses of Variance for Dimensions of Creativity by Religion ................................28

7. Descriptive Statistics for Demographic Variables for Asian Sample ..........................30

8. Descriptive Statistics for Covariate and Criterion Variables in Asian Sample ............31

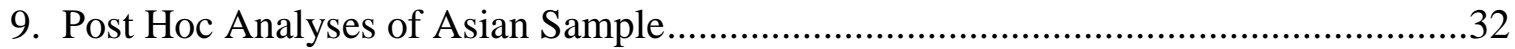




\section{Introduction}

Throughout history, there have been many examples of great creative artwork in religious culture, such as the paintings by Michelangelo in the Sistine Chapel and the sand mandalas by Tibetan Buddhist monks. Does this imply that religion encourages creative artwork, or are creative individuals being called on to create religious pieces? As with most questions from a social psychological perspective, the answer is most likely dependent on the situation. However, psychology still attempts to provide predictions about human behavior by studying relationships between religion, religiosity, and variables such as sexual behavior (Albrecht, Chadwick, \& Alcorn, 1977), deviance (Burdette, Ellison, Hill, \& Glenn, 2009), as well as creativity (Berry, 1999; Dollinger, 2007; Saroglou \& Jaspard, 2001; Wulff, 1997).

Many researchers have examined the relationship between religion, religiosity, and creativity. How one measures each construct is dependent on the study itself due to the complex nature of each variable. In academia, creativity can be measured by one's level of eminence. Novel and creative ideas help advance a field. Important contributors to a specific field, such as Watson and Crick who are credited with determining the structure of DNA, are considered highly creative. Feist (1993), who studied personality traits associated with creative scientists, measured scientists' creativity by their level of eminence. Feist found that more eminent scientists were less involved in religious services as children and as adults compared to less eminent scientists. This finding serves as the motivation for the present study, which was to find a relationship between religion and level of religiosity with level of creativity. The present study added to the 
existing research by examining religiosity based on Wulff's (1997) multidimensional theoretical model, elaborating on previous research that often measured religiosity as a single-dimensional construct, and compared creativity levels between Buddhists and Christians.

\section{Creativity}

Researchers have been devoted to trying to understand creativity and what separates a creative individual from the rest of the population. Kronfeldner (2009) defined creativity as a process that includes psychological novelty, originality, spontaneity, usefulness, and adaptive value. This broad definition of creativity has allowed scientists to measure creativity in many different fields and ways, which has complicated the process of accurately describing the traits and processes that a creative individual possess. Some researchers believe that creativity is the ability to have high production levels (Sternberg, 2006). Others have focused on the importance of the environment on facilitating creativity. For these researchers, they evaluate the person's immediate social, intellectual, and cultural context in relation to creativity. A brief presentation of personality, cognitive, and neurobiological studies follows below.

Many researchers have examined creativity in terms of personality traits that an individual possess (Feist, 1998; King, Walker, \& Broyles, 1996; McCrae, 1999; Reuter, Panksepp, Schnabel, Kellerhoff, Kempel, \& Hennig, 2004). These researchers examined personality traits relating to creativity through surveys and interviews with creative individuals. Personality traits of creative individuals could also be assessed through interviews with individuals who interact with creative individuals. Feist's (1998) meta- 
analysis of personality in scientific and artistic creativity studies showed that creative individuals, in general, are "more autonomous, introverted, open to new experiences, norm-doubting, self-confident, self-accepting, driven, ambitious, dominant, hostile, and impulsive" (p. 299). In particular, high levels of openness to experience have been consistently demonstrated to be related to high levels of creativity.

Another subset of creativity researchers has tried to describe creativity and the creative process from a cognitive perspective. The two main perspectives that attempt to explain the creative process is the systematic and the nonsystematic view (Hass, Weisberg, \& Choi, 2010; Mumford \& Antes, 2007; Simonton, 2007; Smith, Ward, \& Finke, 1995; Sternberg, 2006). The nonsystematic view suggests that the creative process is unpredictable and sometimes chaotic (Simonton, 2007). The systematic view advocates that creativity is a result of knowledge, expertise, and problem solving (Hass et al., 2010; Mumford \& Antes, 2007; Smith et al., 1995; Sternberg, 2006). Both sides of the argument examine notes of creative individuals and analyze whether the resulting creative ideas were produced unexpectedly or through very methodic ways.

Biological and neurological factors have also been studied in regards to creativity (Dietrich \& Kanso, 2010; Ellamil, Dobson, Beeman, \& Christoff, 2012; Fisher, Mohanty, Herrington, Koven, Miller, \& Heller, 2004; Jung, Grazioplene, Caprihan, Chavez, \& Haier, 2010; Lindell, 2011; Sawyer, 2011). In Dietrich and Kanso's (2010) and Sawyer's (2011) review of neuroimaging studies, both concluded that creativity abilities are not localized in the right hemisphere as once believed. Different areas of the brain seem to be activated during creativity tasks. This could be a result of the fact that there is no one 
"correct" method of measuring creativity as evident by the many ways of measuring creativity. Jung et al. (2010) looked at axonal integrity in white matter in the brain in relation to divergent thinking and openness. Axonal integrity is defined as the level of axonal coherence and myelination. They found a significant inverse relationship between divergent thinking and the axonal integrity in the left inferior frontal white matter, and openness was inversely related to the axonal integrity in the right inferior frontal white matter. This finding suggests a relationship between axonal integrity and certain creative traits. The nature of this relationship has not been determined. Whether a predisposition to a certain level of axonal integrity or any other biological predisposition produces creative traits is unclear. What can be concluded from neuroimaging studies is that creativity is not localized in the right hemisphere; what is evident is creativity involves the interaction of both hemispheres.

As demonstrated, there are many different approaches to studying creativity. Creativity in the present study was measured with drawing activities. Five dimensions were examined: fluency, originality, elaboration, abstractness of title, and resistance to premature closure. Fluency is a measure of production; it refers to the number of different pictures drawn. Originality refers to how uncommon the picture is compared to a list of commonly drawn responses. Elaboration is the amount of extra detail incorporated into the picture. Abstractness of title was scored by examining how complex or abstract the title of each picture is compared to a simple title. Resistance to premature closure refers to psychological openness. This was determined by examining 
how complex the picture was drawn. The averaged standardized scores of the five dimensions gave an average creativity score.

\section{Religion and Religiosity}

Religion has been part of human nature for tens of thousands of years in all cultures. To define religion, however, is notoriously difficult for any academic writer. It could be discussed philosophically, psychologically, or anthropologically. Beyer (2006) discussed two ways of defining religion - substantively and functionally. Substantive definitions seek to define what religion is, focusing on the supernatural aspects of religion, while functional definitions focus on religion's social or psychological purposes and effects (Beyer, 2006). Beyer pointed out that to "observe religion as a social phenomenon is to observe it as a communication" (p. 4). It is a communication of rules, norms and prohibitions that its believers are supposed to respect (Saroglou, Corneille, \& Cappellen, 2009). There are also formal definitions of religion that describe religious traditions, such as doctrine, ethics, and scripture.

Religion and religiosity, which is the level of commitment or involvement in one's religion, have been correlated to many aspects of human life, ranging from sexual behavior (Burdette et al., 2009), social deviance (Albrecht et al., 1977; Stack \& Kanavy, 1983), and well-being (Stark, Doyle, \& Rushing, 1983; Vilchinsky \& Kravetz, 2005), due to its relationship and influence on culture and social norms. Burdette et al. (2009) found religious affiliation to be related to patterns of sexual activities of college students. Nonactive Catholic women were more likely to have had a casual sexual encounter than women without religious affiliation. Conservative Protestant college women were less 
likely to have had casual sexual experiences than women with no religious affiliation. Women who went to colleges with Catholic affiliations were more likely than women at a school with no religious affiliation to have had casual sexual activities. Albrecht et al. (1977), in a study of deviance amongst Mormon teenagers, found a negative correlation between participation in religious activities and deviant behavior (i.e., the higher the participation, the lower the level of deviance) in both girls and boys. For girls, deviant behavior that did not directly harm a victim was best predicted by religious involvement. For boys, however, religious involvement was the second best predictor for deviant victimless behavior following peer influence.

In many of the early studies, religiosity was measured by examining an individual's frequency of church attendance and involvement. Measuring religiosity has evolved to examine more meaningful factors such as spirituality, extrinsic and intrinsic motivations, and belief in transcendence. One of the most widely used and referred-to scales is Allport's intrinsic-extrinsic scale, which measures whether an individual's motivation for religious involvement are intrinsically or extrinsically driven (Wulff, 1997). Intrinsically driven individuals internalize religious beliefs and values and are motivated to be religious for more "mature" reasons. Individuals motivated by extrinsic reasons participate in religious activity for self-centered reasons such as safety, solace, or sociability. These two categories, once considered to be polar opposites, have been shown to be related (Wulff, 1997). There is also growing evidence against the notion of a single intrinsic-extrinsic dimension - that the intrinsic-extrinsic dimension is more complicated than previously believed (Neyrinck, Lens, Vansteenkiste, \& Soenens, 2010; 
Wulff, 1997). Neyrinck et al. (2010) measured the relationship between Allport's intrinsic-extrinsic scale to the Religious Motivation Scale, another well-established motivation scale based on the self-determination theory. They concluded that Allport's scale failed to adequately distinguish between intrinsic and extrinsic motivations when compared to the Religious Motivation Scale. Allport's intrinsic scale was found to be a mixture of religious belief orientation, internalized regulation for religion and religious beliefs, and a more flexible interpretation of belief contents. For these reasons, more complex models are needed to accurately measure religiosity (Neyrinck et al., 2010; Wulff, 1997).

Contemporary views about religiosity now include cognitive and social perspectives, one of which is described by Wulff (1997). Wulff's model contains two dimensions. One dimension looks at the inclusion or exclusion of transcendence. This measures the "degree to which the objects of religious interest are explicitly granted participation in a transcendent reality, or to the contrary, are limited to processes immanent within the mundane world" (Wulff, 1997, p. 634). This dimension measures an individual's tendency to believe in a transcendent reality. To believe in a transcendent reality is to believe in the supernatural - that there is a reality beyond the physical world.

The second dimension is the literal versus symbolic interpretation dimension. This measures whether the individual interprets religious content literally or symbolically. To interpret religious content literally is to approach it in a dogmatic, traditional fashion. An example of literal interpretation is reading a religious text and following it exactly without taking into account possible situational differences between when the religious 
text was written and the present situation. Symbolically interpreting religious content is the opposite - interpretation in an open and personalized fashion. For example, one reads a religious story, understands the overall lesson of the story, and then applies the overall lesson so that it appropriately fits the current situation. Exact replication of the behavior from the religious story may not be performed, but the teachings of the story are retained.

The two dimensions combine to create four categories that a person may be classified as when measuring their religiousness: literal affirmation, literal disaffirmation, restorative interpretation, and reductive interpretation. Literal affirmation refers to an individual who believes in the literal existence of the religious realm. An individual who interprets religious content literally and rejects the transcendental realm would be associated with literal disaffirmation. Restorative interpretation refers to one who accepts the existence of the religious realm and searches for the symbolic meaning of religious content. Reductive interpretation denies the existence of transcendence but believes in the symbolic interpretation of religious content for fundamental, positive meaning. Wulff's (1997) model is progressive compared to previous models and was used to measure religiosity in the present study.

\section{Creativity, Religiosity, and Religion}

Several researchers have alluded to the existence of a relationship between level of religiosity and different types of creativity (Berry, 1999; Dollinger, 2007; Lehman \& Witty, 1931; Saroglou \& Jaspard, 2001; Wulff, 1997). Lehman and Witty (1931) looked specifically at scientific eminence and church membership. They examined church membership for 1,189 scientists considered to be outstanding in their respected fields. Of 
the 1,189 scientists, only $25 \%$ reported their church membership. Lehman and Witty were not able to determine whether this was due to scientists not identifying with a church or because the scientists did not consider the information regarding their membership important enough to report. They also found that certain religions had higher proportions of eminent scientists than other religions. Specifically, Unitarians had the highest proportional representation whereas Baptists, Lutherans and Roman Catholics had the lowest. Lehman and Witty used this finding to support the idea that the "more liberal denominations provide many more eminent research men than do the less liberal ones" (p. 548). In this context, liberal means to have relative freedom in interpreting religious matters.

Berry (1999) addressed the patterns of religious background for creativity in the arts and sciences and used expertise and knowledge as an index of creative ability. He compiled data on Nobel Prize winners and their religious backgrounds. Berry found that Protestants were more productive in the sciences than were Catholics, and Catholics were more productive than Protestants in the field of art. This study gives the impression that religion can have an influence on creativity; the nature of how religion can influence creativity depends on the type of religion.

More recent researchers examined the relationship between religion and creativity directly, but many of these studies contain assumptions that are flawed, which questions the validity of their conclusions. For example, Dollinger (2007) attempted to correlate creativity with religion. He measured religiosity in terms of conservatism. He found a negative correlation between conservatism with his measures of creativity, which 
included a survey asking participants' about their involvement with various creative activities, a drawing activity, and a photography activity. This finding cannot be concluded as evidence for the assumed relationship between creativity and religiosity because a conservative person is not always religious, and a religious person is not always conservative.

Saroglou and Jaspard (2001) attempted to show experimentally that religion can inhibit humor creation. They showed the control group a neutral video, one experimental group a religious video, and another experimental group a humorous video. The participants were then given a humor creation task in which they were asked to create of list of responses to daily life frustrations. The responses were scored for attempts at humor and frequency of humor attempts. The humor group had significantly higher creativity scores than did the religious and control group, leading Saroglou and Jaspard to conclude that religion can inhibit creativity, specifically humor creation. However, this conclusion is not warranted. If being exposed to religious content would inhibit humor creation, then the religious condition should not have similar scores to the control group because the control did not see a video that should have also inhibited their creativity scores. In their study, the control and religious condition group did not score significantly different from each other, suggesting that the religious group had the same creativity level as the control group, not lower levels of creativity as Saroglou and Jaspard suggested.

Many of the previous studies have concluded that there is a relationship between creativity and religion or religiosity without adequately measuring one or both variables. 
The present study attempted to further the field by examining this relationship using Wulff's (1997) multidimensional model of religiosity as opposed to the singledimensional scales of religiosity used in previous research. The relationship between type of religion and creativity was also examined in this study.

The first research question concerned the relationship between religiosity and creativity. Following Wulff's (1997) model, level of inclusion of transcendence and literal versus symbolic interpretation was measured. It was predicted that individuals who exhibit high religiosity, measured as having high inclusion of transcendence and literal interpretation of religious content, would be correlated with lower levels of creativity. This description of high religiosity can be described as a more fundamentalist, conforming view of religion. My prediction was based on findings that conformity is positively related to the inclusion of transcendence and literal interpretation of religious content (Fontaine, Duriez, Luyten, Corveleyn, \& Hutsebaut, 2005; Muñoz-Garcia \& Saroglou, 2008; Neyrinck, Vansteenkiste, Lens, Duriez, \& Hutsebaut, 2006).

Due to the overwhelming differences between religions, the second research question examined whether individuals of different religious backgrounds have different levels of creativity. The two religious groups examined were Buddhists and Christians. I predicted a significant difference between these two religious groups based on Lehman and Witty's (1931) findings that more liberal denominations provide more freedom for interpretation. Two core values in Buddhism led me to predict that Buddhists would have higher creativity levels: impermanence and mindfulness (Neusner, 2010). Buddhists believe that nothing is permanent and life is in constant flux. This concept 
advocates for Buddhists to be open to change and experiences. Openness, as mentioned earlier, has been shown to be related to creativity. Also advocated by Buddhism is the concept of mindfulness, which is an awareness of one's actions, words, and thoughts (Ellwood \& McGraw, 2002). Being more aware of one's thoughts could lead to being able to recognize creative thoughts when they actually occur. Being encouraged to practice mindfulness and learning to accept impermanence may lead to individuals developing creative skills.

In response to the abundant evidence regarding the positive relationship between the personality trait openness to experience to creativity (Feist, 1998; King et al., 1996; McCrae, 1999; Reuter et al., 2004) as well as dimensions of religiosity (Duriez \& Soenens, 2006; Fontaine et al., 2005; Muñoz-Garcia \& Saroglou, 2008; Neyrinck et al., 2006), participants' openness to experience was measured and accounted for during statistical analysis to show that religiosity and type of religion have an effect on creativity level above and beyond personality traits.

\section{Method}

\section{Participants}

Participants were recruited from the San José State University (SJSU) Psychology 1 subject pool and religious-based campus clubs. A total of 198 students participated. However, only those who self-identified as being raised either Christian or Buddhist were used. This resulted in a sample size of 187. Thirty-six students identified as Buddhist and 151 students identified with some form of Christianity (Catholic, Protestant, or other Christian). Table 1 summarizes descriptive demographic statistics of the sample, 
separated by religion. The average age of the students was 20.21 years $(S D=2.01)$. There were 132 female students. The majority of students were Asian $(n=69)$, followed by White students ( $n=37)$, Hispanic/Latino(a) $(n=33)$, African American $(n=13)$, Native Hawaiian or Pacific Islander $(n=6)$, and Middle Eastern $(n=4)$. Four students marked 'Other' for their ethnicity and 21 students identified with more than one ethnicity. The majority of students identified single as their marital status (95.72\%) and politically moderate $(56.15 \%)$. 
Table 1

Descriptive Statistics for Demographic Variables for All Participants

\begin{tabular}{|c|c|c|c|c|}
\hline & \multicolumn{2}{|c|}{$\begin{array}{c}\text { Buddhists } \\
(N=36)\end{array}$} & \multicolumn{2}{|c|}{$\begin{array}{l}\text { Christians } \\
(N=151)\end{array}$} \\
\hline & $\mathrm{N}$ & $\%$ & $\mathrm{~N}$ & $\%$ \\
\hline \multicolumn{5}{|l|}{ Demographic } \\
\hline \multirow[t]{3}{*}{ Age } & Mean & 20.44 & & 20.16 \\
\hline & $(S D)$ & $(3.07)$ & & $(1.74)$ \\
\hline & Range & $19-36$ & & $19-27$ \\
\hline \multicolumn{5}{|l|}{ Gender } \\
\hline Male & 13 & 36.11 & 41 & 27.15 \\
\hline Female & 22 & 61.11 & 110 & 72.85 \\
\hline \multicolumn{5}{|l|}{ Ethnicity } \\
\hline African American & 0 & - & 13 & 8.61 \\
\hline Asian & 33 & 91.67 & 36 & 23.80 \\
\hline Hispanic/Latino(a) & 0 & - & 33 & 21.85 \\
\hline Middle Eastern & 0 & - & 4 & 2.65 \\
\hline Native Hawaiian or Pacific Islander & 0 & - & 6 & 3.97 \\
\hline White & 0 & - & 37 & 24.50 \\
\hline Other & 1 & 2.78 & 3 & 1.99 \\
\hline Mixed Ethnicities & 2 & 5.56 & 19 & 12.58 \\
\hline \multicolumn{5}{|l|}{ Marital Status } \\
\hline Single & 34 & 94.44 & 146 & 96.69 \\
\hline Married & 0 & - & 1 & .66 \\
\hline Domestic partnership & 0 & - & 2 & 1.32 \\
\hline Couple living together & 1 & 2.78 & 2 & 1.32 \\
\hline \multicolumn{5}{|l|}{ Political Orientation } \\
\hline Very conservative & 0 & - & 3 & 1.99 \\
\hline Conservative & 2 & 5.56 & 20 & 13.25 \\
\hline Moderate & 23 & 63.89 & 82 & 54.30 \\
\hline Liberal & 8 & 22.22 & 37 & 2.45 \\
\hline Very liberal & 1 & 2.78 & 5 & 3.31 \\
\hline None & 0 & - & 1 & .66 \\
\hline
\end{tabular}




\section{Measures}

Creativity. The Torrance Tests of Creative Thinking-Figural Form A (TTCTFigural Form A) was used to assess each participant's creativity (Torrance, 1998). It uses three picture-based exercises to assess five mental characteristics: fluency, originality, elaboration, abstractness of titles, and resistance to premature closure. Activity I asked the participants to construct a picture using a pear shape provided on the page as a stimulus. The second activity required completion of incomplete figures. Activity III asked the participants to create pictures using two parallel lines.

Each participant received a score for each dimension as well as an average creativity score. Fluency, defined as the number of relevant ideas, was determined by how many different pictures were drawn for Activity II and III. Originality was determined by comparing the pictures to a list of common picture ideas. Points were given to drawings that illustrated an object or idea not listed. Elaboration points were given to additional details that went beyond a simple drawing, such as adding smoke to a chimney on a house. Abstractness of title was determined by how complex the title of each drawing was compared to a simple, concrete title. For example, a picture labeled "dog" would not receive a point for abstractness of title. However, if the drawing was labeled "happy, smiling dog," the participant would receive a point for abstractness of title. Resistance to premature closure points were given to pictures that did not use simple lines to create a picture. Instead, these pictures included complex lines and formations. 
Test-retest reliabilities range from .50 to .93 over one- to two-week periods, and from .35 to .73 over three-year periods. Reliability has also be shown through 7-, 12-, 22-, 40-, and 50-year follow-ups of elementary and high school students (Kim, 2006; Runco, Millar, Acar, \& Cramond, 2010; Torrance, 1969, 1972, 1980). These longitudinal results also showed the TTCT to be significant predictors of quality and quantity of creative achievements and creativeness of aspiration. Concurrent validity has been demonstrated by the significant correlations $(p<.01)$ between the TTCT and the Spatial Test of Primary Mental Abilities, and the Gordon Tests of Visual Imagery Control (Gonzales \& Campos, 1997).

Religiosity. A measure of subjective religiosity was assessed by the shortened Post-Critical Belief Scale (PCBS) developed by Duriez, Soenens, and Hutsebaut (2005). The shortened PCBS is an 18-item scale derived from the original PCBS, which had 33 items. It is scored on a 7-point Likert-type scale, measuring how much individuals agree or disagree with a statement regarding their religiosity. The shortened PCBS was shown to have correlations above .90 with the original PCBS. It was found to measure two dimensions of religiosity described by Wulff (1997), inclusion of transcendence and symbolic interpretation, through multidimensional scaling and factor analysis. A high score regarding the inclusion of transcendence indicates a more accepting attitude towards the transcendent reality. An individual high in symbolic interpretation of religious contents will obtain a high score in that dimension.

Religious Affiliation. To measure religious affiliation, each participant was asked to identify which religion they were raised with: (a) Catholic, (b) Protestant, (c) 
Mormon, (d) other Christian, (e) Jewish, (f) Buddhist, (g) Muslim, (f) Hindu, (g) other religion, (h) no religious affiliation (see Appendix A). They were also asked what religion they currently identify with, how many years they have identified with their current religion as well as how strongly they identify with their current religion on a 7point Likert-type scale.

Personality. To measure each participant's level of openness to experience, the Big Five Inventory (BFI) was used (John, Donahue, \& Kentle, 1991). The BFI measures the five main personality traits: openness to experience, conscientiousness, extraversion, agreeableness, and neuroticism. The participants rated on a 5-point Likert-type scale how strongly they identify with a statement regarding their personality. The BFI has been shown to have alpha reliabilities ranging from .75 to .90 , with an average above .80 (John \& Srivastava, 1999). It also has high convergence with other personality scales, such as the NEO-Personality Inventory (John et al., 1991).

\section{Procedure}

Students from SJSU were recruited through an online forum and email announcements asking for self-identified Buddhists and Christians to participate in a study regarding creativity and personality traits. Students in the Psychology 1 subject pool were compensated with course credit. Interested students signed up for a time slot to participate. Their participation took place in reserved rooms on campus. Each session had no more than 10 participants. A consent form informed the participants that they would be participating in a study about creativity and its relation to personal background. They were assured that their responses would be anonymous and confidential. They were 
not told of the study's focus on religion. After signing the consent form, the scales were administered.

Self-identified Christians were given the TTCT, the BFI, PCBS and demographic questions (e.g., age, ethnicity, religious affiliation, etc.). Buddhist participants were given the TTCT, the BFI, and demographic questions. The participants were allowed 30 min to complete the TTCT. There was no time constraint for the BFI, PCBS, or demographic questions. Once completed, the participants were debriefed and thanked for their participation. The TTCTs were scored by the researcher and a trained research assistant. The researcher and research assistant were allowed to score the TTCT-Figural Form A once they obtained at least a .80 reliability with established scores on training data. The BFI, PCBS, and demographic questions were scored and coded by the researcher. Data analysis was conducted by the researcher.

\section{Results}

Two sets of results will be presented. First, results from the first hypothesis, which predicted differences in creativity as a function of level of religiosity in Christian students, will be presented. Results from the second hypothesis predicting differences in creativity between Buddhists and Christians will be presented next.

\section{Hypothesis 1}

Hypothesis 1 predicted that religiosity will significantly account for variance in creativity. Previous research has shown a strong relationship between the personality trait openness to experience and level of creativity. Therefore, participants' level of openness to experience was measured in the current analyses. I predicted that level of 
religiosity, as measured by level of inclusion of transcendence and symbolic interpretation, will account for variance in creativity after controlling for one's level of openness to experience.

Descriptive Statistics. Table 2 describes the means, standard deviations, and range of scores of the predictor and criterion variables for the 149 participants who fully completed each survey. The predictor variables were openness to experience, inclusion of transcendence, and symbolic interpretation. The criterion variables included the five dimensions of creativity (fluency, originality, elaboration, abstractness of titles, and resistance to premature closure) and average creativity. In reference to religiosity, participants averaged a higher score in symbolic interpretation $(M=3.40, S D=1.88)$ than inclusion of transcendence $(M=1.92, S D=2.60)$, suggesting that participants were more likely to interpret religious texts symbolically than believe in a transcendent reality. Examining the 149 participants' scores on inclusion of transcendence and symbolic interpretation resulted with $73.15 \%$ of the sample being classified as restorative interpretation, $14.77 \%$ reductive interpretation, $.77 \%$ literal affirmation, and $.77 \%$ literal disaffirmation. Examining the creativity dimensions, participants averaged highest in elaboration $(M=111.48, S D=17.62)$, indicating that participants scored highest when judged on how elaborate and detailed their drawings were. 
Table 2

Descriptive Statistics for Predictor and Criterion Variables for Christian Sample

\begin{tabular}{lrcc}
\hline & \multicolumn{3}{c}{ Christians } \\
& \multicolumn{1}{c}{$(N=149)$} \\
\cline { 2 - 4 } & Mean & $(S D)$ & Range \\
\hline Predictor & 35.30 & $(6.06)$ & $21-50$ \\
$\quad$ Openness to experience & 1.92 & $(2.60)$ & $-6-7$ \\
Inclusion of transcendence & 3.40 & $(1.88)$ & $-1-9$ \\
Symbolic interpretation & & & \\
& & & \\
Criterion & 97.84 & $(9.34)$ & $74-119$ \\
Average creativity & 102.40 & $(15.36)$ & $62-147$ \\
Fluency & 100.32 & $(16.16)$ & $62-141$ \\
Originality & 111.48 & $(17.62)$ & $76-157$ \\
Elaboration & 92.58 & $(15.54)$ & $53-130$ \\
Abstractness of titles & 82.40 & $(11.25)$ & $53-114$ \\
Resistance to premature closure & &
\end{tabular}

Pearson Correlations. Pearson correlations between all variables are presented in Table 3. Contrary to prediction, openness to experience was not significantly correlated to any variables. Inclusion of transcendence was significantly negatively correlated to symbolic interpretation $(r=-.22, p=.01)$, and positively correlated to fluency $(r=.19, p=.02)$ and average creativity $(r=.19, p=.02)$, indicating that the greater one's level of inclusion of transcendence, the lower one's symbolic interpretation of religious text will be and the higher one's score will be in fluency and average creativity. Symbolic interpretation was significantly negatively correlated to fluency $(r=-.27, p<.01)$ and originality $(r=-.18, p=.03)$, indicating the more one symbolically interprets religious texts, the lower one will score in fluency and originality. 
Table 3

Intercorrelations between Predictor Variables for Christian Sample

\begin{tabular}{lcccrrrrc}
\hline Variables & 2 & 3 & 4 & 5 & 6 & 7 & 8 & 9 \\
\hline 1. Openness to experience & -.10 & .06 & .02 & .02 & .08 & .06 & -.01 & .06 \\
2. Inclusion of transcendence & - & $-.22 * *$ & $.19 *$ & .12 & .12 & .12 & -.01 & $.19 *$ \\
3. Symbolic interpretation & & - & $-.27 * *$ & $-.18 *$ & .03 & .13 & -.16 & -.13 \\
4. Fluency & & & - & $.75 * *$ & $.17 *$ & .11 & $.38 * *$ & $.78^{* *}$ \\
5. Originality & & & & - & .10 & .09 & $.34 * *$ & $.74^{* *}$ \\
6. Elaboration & & & & - & .15 & .03 & $.53 * *$ \\
7. Abstractness of titles & & & & & - & .13 & $.48^{* *}$ \\
8. Resistance to premature closure & & & & & & - & $.54 * *$ \\
9. Average creativity & & & & & & & -
\end{tabular}

Note: $n=149 ; * p<.05, * * p<.01$

Internal Reliability of the TTCT. Examining the intercorrelations of the five dimensions of creativity revealed significant correlations between some of the dimensions. These correlations ranged from .03 - .78. Due to the low correlations between some of the dimensions, regression analyses were conducted with the average creativity score as well as each dimension.

Regression Analyses. The present study aimed to show that religiosity can account for variance in creativity scores. Initially, I planned to conduct a two-step hierarchical multiple regression/correlation (MRC) to analyze the data for significant variance accounted for in creativity scores by religiosity while taking into account openness to experience. Six hierarchical MRCs were to be conducted to account for the six generated creativity scores. The criterion variables would be average creativity, fluency, originality, elaboration, abstractness of titles, and resistance to premature closure. The predictor variables would be openness to experience and the religiosity scores generated for inclusion of transcendence and symbolic interpretation. Openness to experience would be entered in the first step. Inclusion of transcendence and symbolic 
interpretation scores would be entered in the second step to show that even with openness to experience accounted for, religiosity variables can still account for variance in creativity scores. However, openness to experience was not related to any creativity scores. Therefore, simple regression analyses were performed using only the religiosity dimensions, inclusion of transcendence and symbolic interpretation, as predictor variables and the six creativity scores as criterion variables. A summary of the results is presented in Table 4. 
Table 4

Regression Analyses Summary Predicting Dimensions of Creativity

\begin{tabular}{lcccc}
\hline Variables & $R^{2}$ & $r$ & $\beta$ & $s r^{2}$ \\
\hline Average creativity & & & & \\
$\quad$ Religiosity Variables & $.04 *$ & & & \\
$\quad$ Inclusion of transcendence & & $.19 *$ & $.17 *$ & .03 \\
$\quad$ Symbolic interpretation & & -.13 & -.09 & .01
\end{tabular}

Fluency

Religiosity Variables

$.09 * *$

Inclusion of transcendence

Symbolic interpretation

$\begin{array}{ccc}.19 * & .14 & .02 \\ -.27 * * & -.24 * * & .05\end{array}$

Originality

Religiosity Variables

Inclusion of transcendence

Symbolic interpretation

.04

$\begin{array}{lll}.12 & .09 \quad .01\end{array}$

$\begin{array}{lll}-.18 * & -.16 \quad .02\end{array}$

Elaboration

Religiosity Variables

Inclusion of transcendence

.02

Symbolic interpretation

$\begin{array}{lll}.12 & .14 & .02 \\ .03 & .06 & .00\end{array}$

Abstractness of titles

Religiosity Variables

$.04 *$

Inclusion of transcendence

Symbolic interpretation

$\begin{array}{lll}.12 & .16 & .02 \\ .13 & .17 * & .03\end{array}$

Resistance to premature closure

Religiosity Variables

.03

$\begin{array}{llll}\text { Inclusion of transcendence } & -.01 & -.05 & .00\end{array}$

Symbolic interpretation

$-.16 \quad-.17 * \quad .03$

Note: $n=149 ; * p<.05, * * p<.01$

Examining the results for average creativity showed an overall significant

relationship between average creativity and the religiosity variables, $R^{2}=.04, R_{\text {adj }}^{2}=.03$,

$F(2,146)=3.34, p=.04$. The religiosity variables explained $4 \%$ of variance in this 
sample of participants. This indicates that the two religiosity dimensions together significantly accounted for variance in average creativity scores. Inclusion of transcendence had a unique contribution $(\beta=.17, t=2.03, p=.04)$, but symbolic interpretation did not $(\beta=-.10, t=-1.16, p=.25)$. Inclusion of transcendence also had a significant correlation to average creativity, which lends further support that inclusion of transcendence is a statistically significant predictor of average creativity. Further inspection of each creativity dimension showed that religiosity variables were able to account for variance in fluency and abstractness of titles.

There was an overall significant relationship between fluency and the religiosity variables, $R^{2}=.09, R_{\text {adj }}^{2}=.08, F(2,146)=7.36, p<.01$. The religiosity variables explained $9 \%$ of variance in fluency in the sample. Of the two religiosity dimensions, only symbolic interpretation had a unique contribution $(\beta=-.24, t=-2.96, p<.01)$. Symbolic interpretation accounted for approximately $5 \%$ of variance in fluency. Symbolic interpretation's significant unique contribution along with its significant correlation to fluency adds support that one's symbolic interpretation of religious content may predict fluency level.

There was an overall significant relationship between abstractness of titles and the religiosity variables, $R^{2}=.04, R_{\text {adj }}^{2}=.03, F(2,146)=3.11, p=.05$. Religiosity variables were able to account for $4 \%$ of variance in abstractness of title scores in this sample. Inclusion of transcendence did not have a unique contribution $(\beta=.16, t=1.93, p=.06)$, but symbolic interpretation had a significant unique contribution to abstractness of titles score $(\beta=.17, t=2.02, p=.05)$. However, symbolic interpretation did not have a 
significant correlation to abstractness of titles. This could be a result of symbolic interpretation being significantly correlated to inclusion of transcendence, which could have inflated symbolic interpretation's significance. Therefore, symbolic interpretation's relationship to abstractness of titles is still questionable.

There were several instances where one of the religiosity dimensions was significantly correlated with a creativity dimension, but failed to obtain a significant unique contribution, or had a significant unique contribution but a nonsignificant correlation. This could possibly be due to the religiosity dimensions' correlation with each other. When two predictor variables are significantly correlated, overlap of their contributions could cancel out their unique contribution.

Summary. Overall, in Christians, openness to experience did not significantly account for variance in any of the creativity dimensions or the average creativity score. Therefore, it was not included in the regression analyses. Inclusion of transcendence was found to be significantly positively correlated with average creativity and provided a unique contribution for accounted variance, which was opposite of my prediction that high levels of inclusion of transcendence would be related to lower levels of creativity. However, inclusion of transcendence was not a significant variable in the five creativity dimensions. Symbolic interpretation had significant unique contributions and negative correlations to fluency and abstractness of titles, which was also in the opposite direction of my proposed prediction. These results indicate that various dimensions of religiosity can account for variance for different creativity dimensions, but not in the predicted direction. 


\section{Hypothesis 2}

Hypothesis 2 predicted that due to differences in religious teachings, Buddhists and Christians will differ in creativity levels. Specifically, Buddhists will score higher in creativity scores than Christians. Level of openness to experience will be accounted for in the data analysis as a covariate. The criterion variables, again, will be average creativity, fluency, originality, elaboration, abstractness of titles, and resistance to premature closure.

Descriptive Statistics. Table 5 provides the means, standard deviations, and ranges for the covariate and criterion variables for both the Buddhists and Christians. The covariate was openness to experience. The criterion variables were average creativity, fluency, originality, elaboration, abstractness of titles, and resistance to premature closure. The lack of significant variable mean differences indicate that the Buddhist and Christian sample do not differ in level of openness to experience, average creativity, fluency, originality, elaboration, abstractness of titles, and resistance to premature closure. As a result of the nonsignificant correlations between openness to experience and the creativity measures, and the lack of difference in level of openness to experience between Buddhists and Christians, openness to experience was not used as a covariate. 
Table 5

Descriptive Statistics for Variables in Buddhist and Christian Sample

\begin{tabular}{|c|c|c|c|c|c|c|}
\hline & \multicolumn{3}{|c|}{$\begin{array}{c}\text { Buddhists } \\
(N=36)\end{array}$} & \multicolumn{3}{|c|}{$\begin{array}{l}\text { Christians } \\
(N=151)\end{array}$} \\
\hline & Mean & $(S D)$ & Range & Mean & $(S D)$ & Range \\
\hline \multicolumn{7}{|l|}{ Covariate } \\
\hline Openness to experience & 33.42 & $(6.91)$ & $21-50$ & 35.30 & $(6.06)$ & $21-50$ \\
\hline \multicolumn{7}{|l|}{ Criterion } \\
\hline Average creativity & 95.50 & (12.18) & $72-119$ & 97.84 & $(9.34)$ & $74-119$ \\
\hline Fluency & 98.81 & $(17.83)$ & 62- 133 & 102.40 & $(15.36)$ & $62-147$ \\
\hline Originality & 98.06 & (17.16) & $62-130$ & 100.32 & (16.16) & $62-141$ \\
\hline Elaboration & 106.00 & $(21.58)$ & $65-157$ & 111.48 & (17.62) & $76-157$ \\
\hline Abstractness of titles & 95.89 & $(15.28)$ & $69-133$ & 92.58 & (15.54) & $53-130$ \\
\hline Resistance to premature closure & 78.75 & $(14.67)$ & $53-108$ & 82.40 & $(11.25)$ & $53-114$ \\
\hline
\end{tabular}

Analysis of Variance. The second hypothesis predicted there will be a difference in creativity levels between Buddhists and Christians. Analysis of variance (ANOVA) was conducted to test for differences in creativity scores between Buddhists and Christians. Religion (Buddhist or Christian) was entered as the predictor variable. The criterion variables were the six creativity variables: average creativity, fluency, originality, elaboration, abstractness of titles, and resistance to premature closure. Six ANOVAs were conducted to account for the six criterion variables. This test will illustrate whether one's religion can account for differences in creativity. Results are summarized in Table 6. No significant differences were found in the six creativity scores as a function of religion. Therefore, no support was generated for my second hypothesis. There were no differences in creativity scores between Buddhists and Christians. 
Table 6

Analysis of Variance for Dimensions of Creativity by Religion

\begin{tabular}{|c|c|c|c|c|c|}
\hline Source & $S S$ & $d f$ & $M S$ & $F$ & $p$ \\
\hline \multicolumn{6}{|l|}{ Average creativity } \\
\hline Between groups & 158.60 & 1 & 158.60 & 1.61 & .21 \\
\hline Within groups & 18274.13 & 185 & 98.78 & & \\
\hline Total & 18432.73 & 186 & & & \\
\hline \multicolumn{6}{|l|}{ Fluency } \\
\hline Between groups & 375.03 & 1 & 375.03 & 1.49 & .22 \\
\hline Within groups & 46515.80 & 185 & 251.44 & & \\
\hline Total & 46890.82 & 186 & & & \\
\hline \multicolumn{6}{|l|}{ Originality } \\
\hline Between groups & 148.78 & 1 & 148.78 & .56 & .46 \\
\hline Within groups & 49474.63 & 185 & 267.43 & & \\
\hline Total & 49623.41 & 186 & & & \\
\hline \multicolumn{6}{|l|}{ Elaboration } \\
\hline Between groups & 871.96 & 1 & 871.86 & 2.57 & .11 \\
\hline Within groups & 62847.67 & 185 & 339.72 & & \\
\hline Total & 63719.63 & 186 & & & \\
\hline \multicolumn{6}{|c|}{ Abstractness of titles } \\
\hline Between groups & 317.74 & 1 & 317.74 & 1.33 & .25 \\
\hline Within groups & 44380.27 & 185 & 239.89 & & \\
\hline Total & 44698.01 & 186 & & & \\
\hline \multicolumn{6}{|c|}{ Resistance to premature closure } \\
\hline Between groups & 388.12 & 1 & 388.12 & 2.71 & .10 \\
\hline Within groups & 26521.11 & 185 & 143.36 & & \\
\hline Total & 26909.23 & 186 & & & \\
\hline
\end{tabular}

Note: $n=187$

Due to the overwhelmingly disproportional number of Asian students in the Buddhist sample, post hoc analyses were conducted involving only data from the Asian students from the Buddhist and Christian sample. This was conducted to hold ethnicity constant in the analyses. Again, it was predicted that Buddhists would have significantly 
higher creativity scores than Christians after taking into account level of openness to experience. Data from 69 students were used for the post hoc analyses. There were 33 Buddhists and 36 Christians. A summary of the age, gender, ethnicity, marital status, political orientation, and mean scores for the covariate and criterion variables for Asian Buddhists and Christians is presented in Tables 7 and 8. Again, significant variable mean differences were lacking, indicating that the Asian Buddhist and Christian sample did not differ in regards to level of openness to experience, average creativity, fluency, originality, elaboration, abstractness of titles, and resistance to premature closure. 
Table 7

Descriptive Statistics for Demographic Variables for Asian Sample

\begin{tabular}{|c|c|c|c|c|}
\hline & \multicolumn{2}{|c|}{$\begin{array}{c}\text { Buddhists } \\
(N=33)\end{array}$} & \multicolumn{2}{|c|}{$\begin{array}{l}\text { Christians } \\
(N=36)\end{array}$} \\
\hline & $\mathrm{N}$ & $\%$ & $\mathrm{~N}$ & $\%$ \\
\hline \multicolumn{5}{|l|}{ Demographic } \\
\hline \multirow[t]{3}{*}{ Age } & Mean & 20.48 & & 19.94 \\
\hline & $(S D)$ & $(3.19)$ & & $(1.69)$ \\
\hline & Range & $19-36$ & & $19-26$ \\
\hline \multicolumn{5}{|l|}{ Gender } \\
\hline Male & 12 & 36.36 & 11 & 30.56 \\
\hline Female & 20 & 60.60 & 25 & 69.44 \\
\hline \multicolumn{5}{|l|}{ Marital Status } \\
\hline Single & 31 & 93.94 & 35 & 97.22 \\
\hline Married & 0 & - & 0 & - \\
\hline Domestic partnership & 0 & - & 0 & - \\
\hline Couple living together & 1 & 3.03 & 1 & 2.78 \\
\hline \multicolumn{5}{|l|}{ Political Orientation } \\
\hline Very conservative & 0 & - & 1 & 2.78 \\
\hline Conservative & 1 & 3.03 & 5 & 13.89 \\
\hline Moderate & 21 & 63.64 & 17 & 47.22 \\
\hline Liberal & 8 & 24.24 & 12 & 33.33 \\
\hline Very liberal & 1 & 3.03 & 1 & 2.78 \\
\hline
\end{tabular}


Table 8

Descriptive Statistics for Covariate and Criterion Variables in Asian Sample

\begin{tabular}{|c|c|c|c|c|c|c|}
\hline & \multicolumn{3}{|c|}{$\begin{array}{c}\text { Buddhists } \\
(N=33)\end{array}$} & \multicolumn{3}{|c|}{$\begin{array}{c}\text { Christians } \\
(N=36)\end{array}$} \\
\hline & Mean & $(S D)$ & Range & Mean & $(S D)$ & Range \\
\hline \multicolumn{7}{|l|}{ Covariate } \\
\hline Openness to experience & 32.76 & $(6.82)$ & $21-50$ & 34.94 & $(5.48)$ & $22-45$ \\
\hline \multicolumn{7}{|l|}{ Criterion } \\
\hline Average creativity & 95.36 & $(12.20)$ & $72-119$ & 98.61 & $(8.82)$ & $79-117$ \\
\hline Fluency & 99.09 & (17.63) & $62-133$ & 104.06 & (14.69) & $79-147$ \\
\hline Originality & 97.76 & $(17.27)$ & $62-130$ & 102.39 & (16.94) & $65-138$ \\
\hline Elaboration & 105.58 & (22.49) & $65-157$ & 111.33 & (20.62) & $76-157$ \\
\hline Abstractness of titles & 95.73 & $(15.83)$ & $69-133$ & 91.92 & (16.34) & $53-122$ \\
\hline Resistance to premature closure & 78.64 & $(14.72)$ & $53-108$ & 83.36 & $(11.12)$ & $62-108$ \\
\hline
\end{tabular}

Six ANCOVAs were to be conducted to account for the six criterion variables with openness to experience as the covariate. The criterion variables were the six measures of creativity. The post hoc analyses will illustrate whether one's religion can account for variance in creativity above and beyond openness to experience among Asians. However, openness to experience was a significant covariate only for elaboration. Therefore, simple ANOVAs were conducted for all creativity variables instead of ANCOVAs. The results are summarized in Table 9. No significant differences in creativity scores were found using only the Asian participants. 
Table 9

Post Hoc Analysis of Variance of Asian Sample

\begin{tabular}{|c|c|c|c|c|c|}
\hline Source & $S S$ & $d f$ & $M S$ & $F$ & $p$ \\
\hline \multicolumn{6}{|l|}{ Average creativity } \\
\hline Between groups & 182.26 & 1 & 182.26 & 1.63 & .21 \\
\hline Within groups & 7480.62 & 67 & 111.65 & & \\
\hline Total & 7662.87 & 68 & & & \\
\hline \multicolumn{6}{|l|}{ Fluency } \\
\hline Between groups & 424.37 & 1 & 424.37 & 1.63 & .21 \\
\hline Within groups & 17492.62 & 67 & 261.08 & & \\
\hline Total & 17916.99 & 68 & & & \\
\hline \multicolumn{6}{|l|}{ Originality } \\
\hline Between groups & 369.30 & 1 & 369.30 & 1.26 & .27 \\
\hline Within groups & 19586.62 & 67 & 292.34 & & \\
\hline Total & 19955.91 & 68 & & & \\
\hline \multicolumn{6}{|l|}{ Elaboration } \\
\hline Between groups & 570.75 & 1 & 570.75 & 1.23 & .27 \\
\hline Within groups & 31060.06 & 67 & 463.58 & & \\
\hline Total & 31630.81 & 68 & & & \\
\hline \multicolumn{6}{|c|}{ Abstractness of titles } \\
\hline Between groups & 250.01 & 1 & 250.01 & .97 & .33 \\
\hline Within groups & 17345.30 & 67 & 258.89 & & \\
\hline Total & 17595.30 & 68 & & & \\
\hline \multicolumn{6}{|c|}{ Resistance to premature closure } \\
\hline Between groups & 384.35 & 1 & 384.35 & 2.29 & .14 \\
\hline Within groups & 11263.94 & 67 & 168.12 & & \\
\hline Total & 11648.29 & 68 & & & \\
\hline
\end{tabular}

Note: $n=69$

Summary. Creativity scores did not differ significantly between Buddhists and Christians after openness to experience was held constant. The overwhelmingly large proportion of Asian Buddhist participants led to analyses using only Asian participants 
from both religions. After ethnicity was controlled for, creativity scores, again, did not differ between the two religion groups.

\section{Discussion}

The purpose of this study was to examine the relationship between creativity, religiosity, and religion. I sought to examine this relationship using more appropriate measures and extend previous research that suggested a negative relationship between creativity and religiosity. Religiosity was evaluated using a bi-dimensional scale measuring one's inclusion of transcendence and level of symbolic interpretation of religious texts. The complex nature of creativity inspired me to look at creativity multidimensionally. I used the Torrance Tests of Creative Thinking (Torrance, 1969, 1972, 1980) to examine creativity within five dimensions: fluency, originality, elaboration, abstractness of titles, and resistance to premature closure. The data yielded interesting results that provided some support for the existence of a relationship between religiosity and creativity.

There was some support for the prediction that religiosity accounted for variance in creativity. Level of inclusion of transcendence explained a significant amount of variance in average creativity scores. Those who believe in a transcendent reality had higher creativity scores, opposite of my prediction. Perhaps to believe in a transcendent reality, one needs to maintain an open mind for the existence of the unknown; an open mind has been shown to be related to higher creativity. Level of symbolic interpretation of religious contents explained a significant amount of variance in several dimensions of creativity. Specifically, fluency and abstractness of titles had unique contributions from 
level of symbolic interpretation. The negative relationship between fluency and symbolic interpretation suggests the more symbolically one interprets religious texts, the lower the number of ideas one will have. This result was the opposite of the proposed nature and direction of the relationship between religiosity and creativity. Perhaps there is a mediating factor that explains this relationship that has yet to be discovered. Also opposite of my prediction was the lack of differences in creativity scores between Buddhists and Christians. After holding openness to experience and ethnicity constant, no difference in creativity scores was seen, suggesting that type of religion may not affect creativity levels. Instead, level of religiosity may account for differences in different creativity dimensions.

\section{Implications of Findings}

There are several theoretical and practical implications that can be derived from this study's results. First, openness to experience was not significantly correlated to any of the creative dimensions in any of the analyses. This contradicts previous researchers advocating a strong relationship between the two variables. Perhaps openness to experience is related to certain creative tasks, but not with the TTCT.

Second, the mixed results concerning the relationship between religiosity and creative dimensions indicate that the relationship is more complex than previously believed by researchers, as evident by the simplistic measures used in previous studies. Future researchers attempting to describe this relationship will have to account for the various dimensions that comprise each construct. Religiosity cannot be continued to be seen as a variable that can be easily measured through simple questions such as how 
often one attends religious service. Aspects pertaining to psychological and intellectual dimensions must be examined when measuring religiosity. The same applies to creativity. Creativity must also be examined through many lenses to account for the complexity of creative ability or skill. Creativity is not simply a result of having many ideas or having original ideas; it is a combination of many factors including how elaborate one thinks, how abstract one's ideas are, and one's resistance to being closed-minded. Examining multiple dimensions within each construct complicates how future researchers will measure each construct but will provide a richer understanding of the relationship between religiosity and creativity.

The nonsignificant results from the second hypothesis and the post hoc analyses also provide theoretical implications, suggesting that Buddhism and Christianity do not affect creativity levels differently. This conclusion goes against previous researchers suggesting different religions produce different types of creative individuals. However, previous researchers did not examine Buddhist individuals. Therefore, conclusions from previous research may not be applicable when comparing Buddhists and Christians. Also, due to the low sample size of Buddhist participants, further research is required to determine the actual relationship between Buddhism and creativity level compared to Christians.

The combination of results from this study suggests that certain types of religions may not have different effects on creativity. What seems to matter in regards to creativity is one's level of religiosity, which may have different effects on different aspects of creativity. 


\section{Strengths and Weaknesses}

There were several strengths and weaknesses of this study. A strength of the study is the use of multidimensional definitions of the constructs. Acknowledging the complexity that surrounds each construct extends previous research that only examined these constructs uni-dimensionally. Religiosity was examined using two dimensions while creativity was examined using five dimensions. Another strength of this study was the diversity seen in the Christian sample. Previous research typically used White participants in their Christian sample. This study's Christian sample had participants who identified with a variety of ethnic backgrounds, including African American, Asian, and Hispanic/Latino(a). A third strength of this study was the inclusion and examination of Buddhists. This, according to my review of the literature, is the first of its kind to directly compare creativity scores between Buddhists and Christians. Previous studies that compared creativity between religions have typically examined Protestants, Catholics, and Jews. Another strength of the study is how I obtained the creativity scores. Instead of relying on self-reports, participants were asked to perform creatively. This allowed for the researcher and research assistant to assess each individual's creativity level in a more objective manner.

Along with the strengths, there were several weaknesses of this study. First, the sample used was college students from SJSU. This limits the generalization of my results. The results of this study may not be representative of the relationship between creativity, religiosity, and religion for individuals who are not in their twenties in college. Also, because the majority of participants were students participating for course credit, they 
may not have been motivated to perform to the best of their ability. Their creativity scores may not be an accurate representation of their actual creative skills.

Another limitation of the study's generalizability is the lack of variability in religiosity in the sample. Over $70 \%$ of the Christian participants were classified as restorative interpretation, with over $80 \%$ of the sample scoring high on symbolic interpretation. Due to the limited range of religiosity scores, the results may not generalize to the individuals who have differing religiosity levels, especially those who interpret religious texts literally.

Another weakness of the study is the small Buddhist sample, which made it difficult to detect statistical differences in creativity scores between groups. Also, in regards to the sample, the diversity of the Christian sample was generally a strength, but it also made it different from the Buddhist sample, which was comprised mainly of participants of Asian descent. Therefore, cultural differences may have played a role in moderating one's creativity. However, when comparing only Asian participants from each religion, no significant results were found.

Related to the concept of diversity is the wide range of diversity within each religion. Both Buddhism and Christianity have many different sectors within their religions. In Buddhism, one could follow one of many schools of Buddhism, such as Theravada or Mahayana. In Christianity, there are many ways to identify as Christian, such as Catholic, Protestant, Evangelical, et cetera. The diversity within each religion may itself have differing effects on creativity, which would make it difficult to make a conclusion about a particular religion's effects as a whole. 
Another weakness was the absence of measuring religiosity within the Buddhist sample. Religiosity was found to be able to account for variance in some of the creativity dimensions in the Christian sample. Controlling for religiosity when comparing Buddhists and Christians may have been able to help detect differences between the two groups. However, no religiosity scale was found that measures a Buddhist's level of inclusion of transcendence or symbolic interpretation of religious texts.

\section{Future Research}

To advance the field, future researchers should use scales that measure the many dimensions of creativity and religiosity. We showed in this study that different dimensions of religiosity were able to account for variance in different dimensions of creativity. Therefore, looking into the nuances of each construct is critical in understanding the relationship between creativity and religiosity. Also, other types of religiosity measures may help to identify the relationship between religiosity and creativity. The present study hypothesized that those high in religiosity, which can be described as high in fundamentalism, would score lower in creativity. Future researchers may want to use a religiosity scale that examines fundamentalist behaviors directly.

Researchers interested in this research can also extend the field by extending their sample to include individuals of other religions as well as individuals who are known for being creative. Researchers could examine religiosity in those who have already been distinguished for their creative ability. This would allow researchers to compare religiosity between those high in creativity with those who have not achieved creative feats. A religion that would be interesting to include in future research is Judaism. 
Individuals from the Jewish faith are known to be highly over-represented in humor, film, and science. It would be interesting to include a Jewish sample in future studies to see if their over-representation can be translated into creativity scores. When comparing creativity of individuals from different religions, researchers should take into account religiosity level.

Future researchers could also compare different sectors within each religion. Also interesting would be one's cultural background, which could relate to how one interprets religion and religiosity. Some cultures may promote more strict interpretations of religious texts, while some may be more flexible in terms of religious commitment. Future researchers may want to hold cultural background constant in their studies.

\section{Conclusion}

The present study generated some support for the relationship between creativity and religiosity. However, no support was generated for the relationship between type of religion and creativity. Regardless of some of the shortcomings of this study, this study is, to date, the first to examine the relationship between creativity and religiosity using multidimensional scales. It was also the first study to directly compare creativity levels between Buddhists and Christians. More studies are needed to determine whether religiosity and religion can affect on an individual beyond spiritual needs. 


\section{References}

Albrecht, S., Chadwick, B., \& Alcorn, D. (1977). Religiosity and deviance: Application of an attitude-behavior contingent consistency model. Journal for the Scientific Study of Religion, 16(3), 263-274.

Berry, C. (1999). Religious traditions as contexts of historical creativity: Patterns of scientific and artistic achievement and their stability. Personality and Individual Differences, 26, 1125-1135.

Beyer, P. (2006). Religions in global society. New York: Routledge.

Burdette, A., Ellison, C., Hill, T., \& Glenn, N. (2009). "Hooking up" at college: Does religion make a difference? Journal for the Scientific Study of Religion, 48(3), 535-551. doi:10.1111/j.1468-5906.2009.01464.x.

Dietrich, A., \& Kanso, R. (2010). A review of EEG, ERP, and neuroimaging studies of creativity and insight. Psychological Bulletin, 136(5), 822-848. doi:10.1037/a0019749

Dollinger, S. J. (2007). Creativity and conservatism. Personality and Individual Differences, 43, 1025-1035.

Duriez, B., Soenens, B., \& Hutsebaut, D. (2005). Introducing the shortened Post-Critical Belief Scale. Personality and Individual Differences, 38(4), 851-857.

Duriez, B., \& Soenens, B. (2006). Personality, identity styles, and religiosity: An integrative study among late and middle adolescents. Journal of Adolescence, 29, 119-135.

Ellamil, M., Dobson, C., Beeman, M., \& Christoff, K. (2012). Evaluative and generative modes of thought during the creative process. Neuroimage, 59(2), 1783-1794. doi:10.1016/j.neuroimage.2011.08.008

Ellwood, R. S., \& McGraw, B. A. (2002). Many peoples, many faiths. New Jersey: Pearson Education.

Feist, G. (1993). A structural model of scientific eminence. Psychological Science, 4(6), 366-371.

Feist, G. (1998). A meta-analysis of personality in scientific and artistic creativity. Personality and Social Psychology Review, 2, 290-309. 
Fisher, J. E., Mohanty, A., Herrington, J. D., Koven, N. S., Miller, G. A., \& Heller, W. (2004). Neuropsychological evidence for dimensional schizotypy: Implications for creativity and psychopathology. Journal of Research in Personality, 38(1), 2431. doi:10.1016/j.jrp.2003.09.014

Fontaine, J. R. J., Duriez, B., Luyten, P., Corveleyn, J., \& Hutsebaut, D. (2005). Consequences of a multidimensional approach to religion for the relationship between religiosity and value priorities. The International Journal for the Psychology of Religion, 15(2), 123-143.

Fontaine, J. R. J., Duriez, B., Luyten, P., \& Hutsebaut, D. (2003). The internal structure of the Post-Critical Belief Scale. Personality and Individual Differences, 35, 501518.

Gonzales, M. A., \& Campos, A. (1997). Mental Imagery and creative thinking. Journal of Psychology, 131, 357-364.

Hass, R. W., Weisberg, R. W., \& Choi, J. (2010). Quantitative case-studies in musical composition: The development of creativity in popular-songwriting teams. Psychology of Music, 38(4), 463-479.

John, O. P., Donahue, E. M., \& Kentle, R. L. (1991). The big five inventory - Versions $4 a$ and $4 b$. Technical Report, Institute of Personality and Social Research, University of California, Berkeley, CA.

John, O. P., \& Srivastava, S. (1999). The Big Five Trait taxonomy: History, measurement, and theoretical perspectives. In L. A. Pervin, \& O. P. John (Eds.), Handbook of personality: Theory and research (2nd ed., pp. 102-138). New York, NY: Guilford Press.

Jung, R. E., Grazioplene, R., Caprihan, A., Chavez, R. S., \& Haier, R. J. (2010). White matter integrity, creativity, and psychopathology: Disentangling constructs with diffusion tensor imaging. Plos ONE, 5(3). doi:10.1371/journal.pone.0009818

Kim, K. H. (2006). Can we trust creativity tests? A review of the Torrance tests of creative thinking (TTCT). Creativity Research Journal, 18(1), 3-14.

King, L. A., Walker, L. M., \& Broyles, S. J. (1996). Creativity and the five-factor model. Journal of Research in Personality, 30, 189-203.

Kronfeldner, M. (2009). Creativity naturalized. The Philosophical Quarterly, 59(237), 577-592. 
Lehman, H. C., \& Witty, P. A. (1931). Scientific eminence and church membership. Scientific Monthly, 33, 544-49.

Lindell, A. K. (2011). Lateral thinkers are not so laterally minded: Hemispheric asymmetry, interaction, and creativity. Laterality: Asymmetries of Body, Brain and Cognition, 16(4), 479-498.

McCrae, R. R. (1999). Mainstream personality psychology and the study of religion. Journal of Personality, 67(6), 1209-1218.

Mumford, M. D., Antes, A. L., Caughron, J. J., Connelly, S., \& Beeler, C. (2010). Crossfield differences in creative problem-solving skills: A comparison of health, biological and social sciences. Creativity Research Journal, 22(1), 14-26.

Muñoz-Garcia, A., \& Saroglou, V. (2008). Believing literally versus symbolically: Values and personality correlates among Spanish students. Journal of Beliefs \& Values, 29(3), 233-241.

Neusner, J. (2010). Introduction to World Religions. Nashville: Abingdon Press.

Neyrinck, B., Vansteenkiste, M., Lens, W., Duriez, B., \& Hutsebaut, D. (2006). Cognitive, affective and behavioral correlates of internalization of regulations for religious activities. Motivation and Emotion, 30(4), 323-334.

Neyrinck, B., Vansteenkiste, M., Lens, W., \& Soenens, B. (2010). Updating Allport's and Batson's framework of religious orientations: A reevaluation from the perspective of self-determination theory and Wulff's social cognitive model. Journal for the Scientific Study of Religion, 49(3), 425-438.

Reuter, M., Panksepp, J., Schnabel, N., Kellerhoff, N., Kempel, P., \& Hennig, J. (2005). Personality and biological markers of creativity. European Journal of Personality, 19, 83-95.

Runco, M. A., Millar, G., Acar, S., \& Cramond, B. (2010). Torrance Tests of Creative Thinking as predictors of personal and public achievement: A fifty-year follow-up. Creativity Research Journal, 22(4), 361-368.

Saroglou, V. (2002). Religion and the five factors of personality: A meta-analytic review. Personality and Individual Differences, 32, 15-25.

Saroglou, V., Corneille, O., \& Van Cappellen, P. (2009). 'Speak, Lord, your servant is listening': Religious priming activates submissive thoughts and behaviors. International Journal for the Psychology of Religion, 19(3), 143-154. doi:10.1080/10508610902880063. 
Saroglou, V., \& Jaspard, J. M. (2001). Does religion affect humour creation? An experimental study. Mental Health, Religion \& Culture, 4, 33-46.

Sawyer, K. (2011). The cognitive neuroscience of creativity: A critical review. Creativity Research Journal, 23(2), 137-154. doi:10.1080/10400419.2011.571191

Simonton, D. K. (2007). The creative process in Picasso's Guernica sketches: Monotonic improvements versus nonmonotonic variants. Creativity Research Journal, 19(4), 329-344.

Smith, S. M., Ward, T. B., \& Finke, R. A. (1995). The Creative Cognition Approach. Cambridge, MA: MIT Press.

Stack, S., \& Kanavy, M. (1983). The effect of religion on forcible rape: A structural analysis. Journal for the Scientific Study of Religion, 22(1), 67-74.

Stark, R., Doyle, D., \& Rushing, J. (1983). Beyond Durkheim: Religion and suicide. Journal for the Scientific Study of Religion, 22(2), 120-131.

Sternberg, R. J. (2006). Cognitive Psychology (4 ${ }^{\text {th }}$ ed.). United States of America: Thomson Wadsworth.

Torrance, E. P. (1969). Prediction of adult creative achievement among high school seniors. Gifted Child Quarterly, 13, 223-229.

Torrance, E. P. (1972). Predictive validity of the Torrance Tests of Creative Thinking. Journal of Creative Behavior, 6(4), 236-252.

Torrance, E. P. (1980). Growing up creatively gifted: A 22-year longitudinal study. Creative Child and Adult Quarterly, 5, 148-158.

Torrance, E. P. (1998). The Torrance Tests of Creative Thinking norms - technical manual figural (streamlines) forms $A \& B$. Bensenville, IL: Scholastic Testing Service, Inc.

Vilchinsky, N., \& Kravetz, S. (2005). How are religious belief and behavior good for you? An investigation of mediators relating religion to mental health in a sample of Israeli Jewish students. Journal for the Scientific Study of Religion, 44(4), 459471. doi:10.1111/j.1468-5906.2005.00297.x.

Weisberg, R. W. (1995). In S. M. Smith, T. B. Ward, \& R. A. Finke (Eds.), The Creative Cognition Approach (pp. 53-72). Cambridge, MA: MIT Press. 
Wulff, D. M. (1997). Psychology of religion: Classic and contemporary (2 ${ }^{\text {nd }}$ ed.). New York: Wiley. 


\section{Appendix A}

\section{Demographic/Background Items}

Please answer each item as completely as possible.

Year of birth:

Gender: __ Male _ Female

Ethnicity:

African American
American Indian or Alaskan
Asian
_ Hispanic/Latino(a)

Middle Eastern

_ Native Hawaiian or Pacific Islander White

_ Other

Marital status:

Single
Divorced
Married

Widowed
Domestic Partnership

Couple living together

Political orientation:

Very conservative
Conservative
Moderate

Which religion were you raised with?

Buddhist
Catholic
Hindu
Jewish

$\begin{array}{ll} & \text { Mormon } \\ \text { - Muslim } \\ \text { Protestant } \\ \text { Other Christian }\end{array}$

What religion do you CURRENTLY identify with?

Buddhist
Catholic
Hindu
Jewish

$\begin{array}{ll} & \text { Mormon } \\ \text { - } & \text { Muslim } \\ \text { Protestant } & \text { Other Christian }\end{array}$

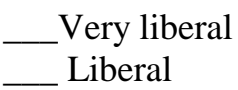

Liberal

If you currently identify with a religion,

(a) how many years have you identified with your current religion?

(b) how strongly do you identify with your religion?

Very strongly

Moderately strongly

Somewhat strongly

Slightly strongly

Not at all strongly

Please check: Did you answer each statement? 